Original Article

\title{
A Comparative Study on Factors Leading To Early Weaning Among Urban and Rural M others of Infants in Selected Community Areas at Mangalore.
}

\section{TeenaJ. Jose ${ }^{1}$, Sujatha $\mathbf{R}^{2}$}

${ }^{1} \mathrm{M}$ Sc (N) Student, ${ }^{2}$ Prof\& HOD, Department of Child Health Nursing, Nitte Usha Institute of Nursing Sciences, Constituent College of Nitte University, Kotekar Beeri Road, Paneer, Deralakatte, M angalore - 575 018, Karnataka, India.

*Corresponding Author: Sujatha R., Prof. \& HOD, Department of Child Health Nursing, Nitte Usha Institute of Nursing Sciences, Constituent College of Nitte University, Kotekar Beeri Road, Paneer, Deralakatte, M angalore - 575 018, Karnataka, India.

E-mail :sujathakannappan@gmail.com

Received

: 15.06 .2016

Review Completed : 15.08.2016

Accepted

: 02.11 .2016

Keywords : Early weaning, mothers, infants, breast feeding, complementaryfeeding.

\begin{tabular}{|c|}
\hline Access this article online \\
\hline Quick Response Code \\
\hline
\end{tabular}

\section{Introduction}

Advice to mothers on when to wean their babies could be tripling the risk of type 1 diabetes in susceptible children, according to new research. According to U.S. scientists both early and late first exposure to solid food is associated with an increased likelihood of developing the autoimmune disease. Early weaning, at less than four months of age, led to a doubling of risk, while introducing solid food later increased the risk three-fold.

New data from the Millennium Cohort Study, following 12,000 children born in 2000 , shows that more than one in four ( 26 per cent) babies given solids before four months were overweight aged three compared with 22 per cent of those fed solids later on.

Poor breast feeding and complementary feeding practices, together with high rates of morbidity from infectious diseases are the prime proximate causes of malnutrition in the first two years of life. The Interventions promoting optimal breast feeding could prevent $13 \%$, while promoting optimal complementary feeding could prevent another $6 \%$ of death in countries with high mortality rates. Poor breast feeding and complementary feeding practices have been widely documented in the developing countries like India. Additionally, $6 \%$ of infants in developing countries are never breast fed.

Breast feeding is nature's way of nurturing the child, creating a strong bond between the mother and the child. It provides developmental and learning opportunities to the infant, stimulating all five senses of the child - sight, smell, hearing, taste, and touch. Breast feeding fosters emotional security and affection with a lifelong impact on psychosocial development. Special fatty acids in breast 
milk lead to increased intelligence quotient and better visual acuity.

The American Academy of Pediatrics recommends that infant should be exclusively breast-fed for approximately the first six months of life. Despite of these given guidelines many women start weaning early due to several contributing factors. In view of the above problems, the purpose of this study is to highlight some of the factors leading early weaning of child in the urban and rural areas of our community.

\section{Objectives of the study}

1. To identify the mothers who have initiated the early weaning in selected rural and urban area.

2. To determine the factors leading to early weaning among the rural mothers of infants.

3. To determine the factors leading to early weaning among the urban mothers of infants.

\section{Hypothesis}

H1: There will be a significant difference between the factors leading to early weaning among mothers of infants between rural and urban area.

\section{Conceptual Frame Work}

The conceptual frame work selected for this study was based on Ernestine Wiedenbach "The helping art of clinical nursing theory". It describes that every individual experiences needs as a part of living. The need is anything the individual may require to maintain or sustain himself comfortably or capability in this situation. A need for help is "any measure or action required and desired by the individual and which has potential for restoring or extending his ability to cope up with the demands implicit in this situation.

Identification of need for help: In this study the researcher explored the factors leading early weaning among the mothers of infants.

Ministration of help: In this study health education on breast feeding was given to the screened mothers to promote exclusive breast feeding after the data collection.
Validation: Further studies are recommended to validate/ to identify whether the need was met or not..

\section{Materials and M ethods}

\section{Research approach}

In this study, survey approach is used to study the factors leading to early weaning among urban and rural mothers of infants in the selected community areas at M angalore

\section{Research design}

Research design selected for the present study was descriptive comparative design.

\section{Setting of the study:}

The present study was conducted in manjanady panjayath (rural area), Mangalore andin bajal (urban area), Mangalore.

\section{Population}

The population of study comprises of mothers of children less than one year of age in urban and rural community area at $M$ angalore.

\section{Sample}

The sample size of the study comprises of 70 early weaned mothers from 300 screened mothers residing at urban area and 50 early weaned mothers from 300 screened mothers of children under 1 year of age from rural area.

\section{Sampling Technique}

Non-probability sampling technique and purposive sampling method was used in the present study.

\section{Data Collection Instruments}

The following instruments were developed by the researchers for the present Study.

\section{Tool 1: Demographic Performa}

Tool 2: A Checklist is to assess the factors leading to early weaning.

It consists of 43 items related to early weaning. Items are listed in 8 parts.

Part-I has 5 items related to cultural trends. 
Part-II has 7 items related to psychosocial influence.

Part-III has 5 items related to common barriers in continuation of breast feeding.

Part-IV has 4 items related to socio economic factors.

Part-V has 3 items related to support from others.

Part-VI has 3 items related to medical problems.

Part-VII has 4 items related to common practices.

Part VIII has 11 items related to the knowledge of the mothers.

\section{Content validity of the tool.}

The prepared tool along with the blue print, objectives are given to 9 experts to ensure the content validity. The experts are from the field of Pediatrics. Suggestions and recommendations given by the experts are accepted and necessary corrections are done for modifying the tool.

\section{Reliability}

Split half technique is used to find out the reliability of the present study. The checklist is administered to 12 mothers.

The test result is divided into two equivalent halves (as odd and even groups) and correlation for the half test is calculatedusing Karl Pearson Correlation Coefficient formula, and significance of correlation is tested using Spearman Brownprophesy formula. The ' $r$ ' value is 0.87 and the tool is found to be reliable.

\section{Pilot study}

Pilot study is conducted in rural and urban communities of $M$ angalore. To find the feasibility of the study, 12 samples i.e. six rural women and six urban women were selected using non probability purposive sampling method. The subjects of the pilot study 36 possessed the same characteristics as that of the sample for the final study but are not included in the main study. After conducting the pilot study it is found that the study is feasible. It is also found that the subjects are cooperative, the tool is relevant and the cost of the study is within the limit.

\section{Data Collection Process}

The studywas conducted in manjanady (rural area) andBajal (urban area)in M angalore. Formalpermission was obtained from the District Medical Officer, Mangalore. Data was collected between 17-9-2012 to 3-11-2012 from mothers who have children less than one year of age and those who know English/ Kannada/ Malayalam. The investigator had given a brief introduction before collecting the data. Confidentiality was assured to the entire subjects to get their co-operation. An informed consent was taken from all the mothers individually after explaining the purpose and objectives of the study. Mothers were explained how to fill the demographic proforma, and check list.

\section{Protection of Human Subjects}

The study proposal was presented to the ethical committee of Nitte University for Ethical clearance.

\section{Statistical Methods}

The plan for data analysis were:

Section 1: Demographic characteristics will be analyzed by using frequency and percentage distribution.

Section 2: Factors leading to early weaning will be analyzed by descriptive statistics.

\section{Results}

Majority of the rural $37(53 \%)$ and urban $26(52 \%)$ mother belongs to the age group of $26-30$ years.

Majority of rural 28(56\%) women and urban 24 (34.3) women studied up to high school education.

Majority of rural 126 (52\%) women and urban $37(53 \%)$ women belongs to Hindu religion.

M ajority of urban 35(50\%) and rural 27(54\%) mothers are private employees.

M ajority of urban 32(46\%) and rural 22(44\%) mothers are having a monthly family income of between RS.7594RS.11361.

Majority of early weaned mothers from urban 55 (78.6) and rural 40 (80\%) area belongs to the nuclear family. 
Most of the urban $34(49 \%)$ mothers have one child and most of the rural $40(80 \%)$ mothers have two children.

M ajority of the urban 36(51.4) mothers are primi paras and equal number of the rural $25(50 \%)$ mothers are primi paras and multiparas.

Figure 1

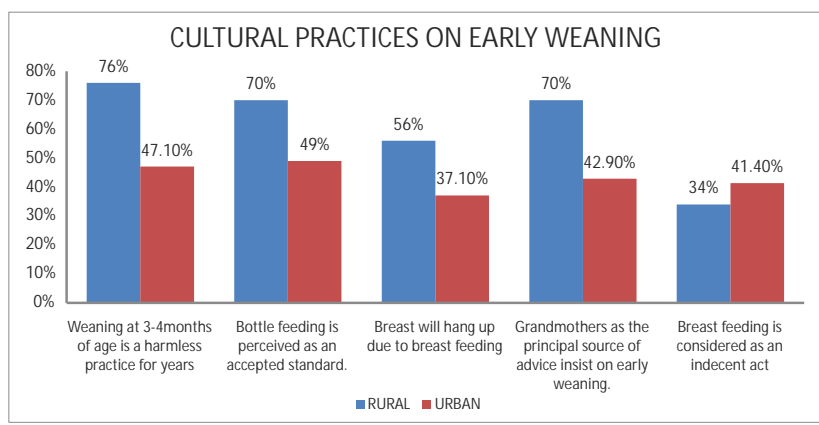

Frequency and percentage distribution of rural and urban women according to cultural practice

Regarding the cultural practices about early weaning the present study result shows that among rural women 38 (76\%) mothers answered that weaning at 3-4 months of age is a harmless practice, $35(70 \%)$ of mothers reports that grandmothers were the principal source of adviser in early weaning, and there is only 17 (34\%) mothers considers that breast feeding is considered as an indecent act.

Among urban mothers reveals that most of the mothers 34 (49\%) mothers believes that bottle feeding is perceived as an accepted standard,33 (47.1\%) believes that weaning at 3-4 months of age is a harmless practice for years and only 26 (37.1\%) of mothers are having the perception that breast will hang up due to breast feeding.

Figure 2

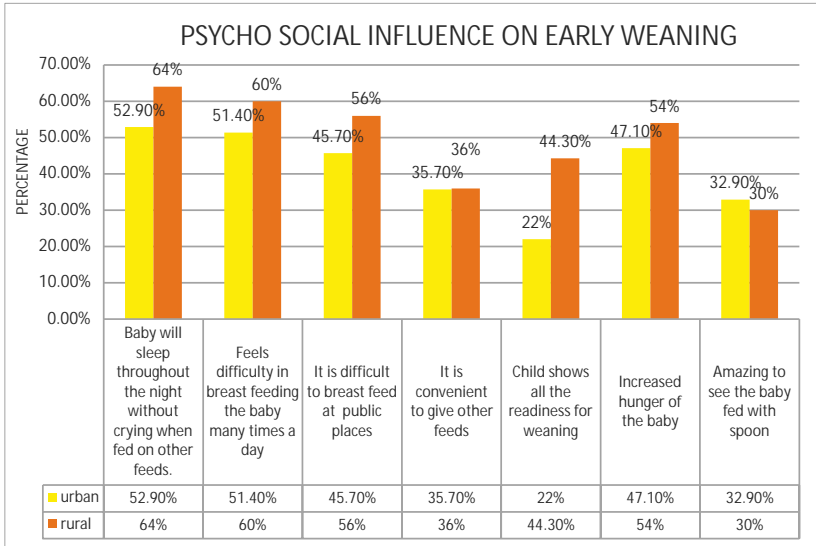

Frequency and percentage distributions of rural and urban women according to psycho-social Influence

Assessment of psychosocial influence among rural mothers reveals that 32(64\%) mothers initiated early weaning because of baby will sleep throughout night without crying when fed on another feeds,30 (60\%) mothers felt difficulty in breast feeding the baby many times a day and only 11 (22\%) mothers reports that child showsall the readiness for weaning.

Among urban mothers reveals that 37 (53\%) of mothers thinks that baby will sleep throughout night without crying when fed on another feed, 36 (51.4\%) mothers early weaned their children because they feels difficulty in breastfeeding the baby many times a day and only 23 (33\%) mothers reported that they enjoyed feeding the baby with the spoon.

\section{Figure 3}

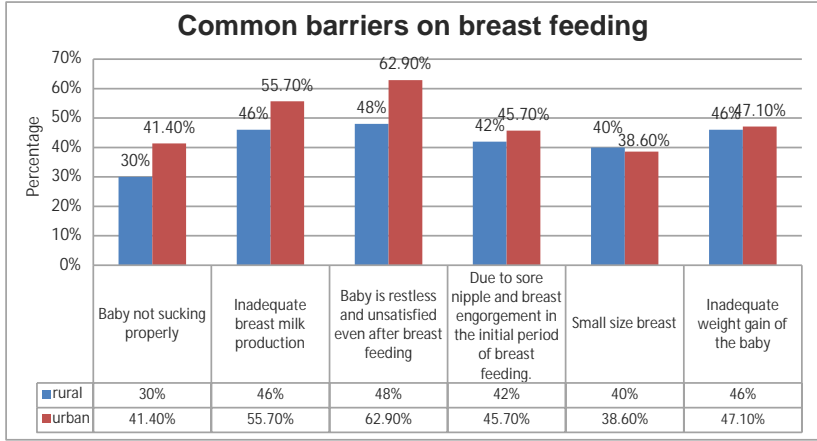

Frequency and percentage distribution of rural and urban women according to common barriers in continuation of breast feeding

Assessment of common barriers in continuation of breast feeding shows that $24(48 \%)$ of mothers initiated early weaning because of their baby is restless and unsatisfied even after breast feeding, $23(46 \%)$ of mothers reports that there was inadequate breast milk production and inadequate weight of the baby, and only 15 (30\%) of mothers reported that baby was not sucking properly. Among urban mother's shows that 44 (63\%) mothers early weaned their children because of Baby's restlessness and unsatisfied even after breast feeding, 39 (56\%) of mothers had in adequate breast milk production and only 27 (39\%) mothers reported that small size breast was the hindering factor.

Figure 4

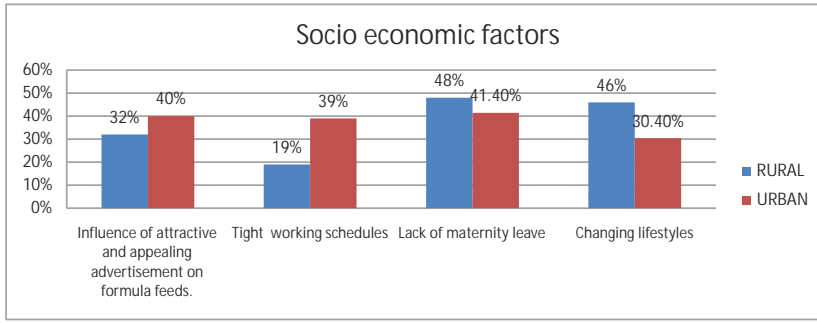

Frequency and percentage distribution of rural and urban women according to socio economic factors

Assessment of socio economic factors influencing early weaning reveals that $24(48 \%)$ rural mothers initiated early weaning because of lack of maternity leave,23 (46\%) because of changes in 
the life style and only 19 (38\%) of mothers initiated early weaning because of tight working schedules.

Among urban mothers around 29 (41.4\%) early weaned because of lack of maternity leave, 28 (40\%) mothers early weaned because of influence of attractive and appealing advertisement on formula feeds and only 21 (30.4\%) mothers early weaned because of change in life styles.

Table 1 : Frequency and percentage of mothers early weaned in urban and rural areas

$n=600$

\begin{tabular}{|l|c|c|c|}
\hline Area & Screened mothers $(\mathrm{n})$ & \multicolumn{2}{|c|}{ Early weaned mothers } \\
\cline { 3 - 4 } & & 70 & $23 \%$ \\
\hline Urban & 300 & 50 & $17 \%$ \\
\hline Rural & 300 & Frequency & Percentage (\%) \\
\hline
\end{tabular}

The data presented in table 1 shows that around 300 mothers of infants from rural area and 300 mothers of infants from urban area were screened and early weaned mothers were identified as 70 (23\%) mothers from urban area and $50(17 \%)$ mothers from rural areas were selected as samples.

Table 2 : Frequency and percentage distribution of rural and urban mothers according to support groups

Assessment of weaning associated with support from others reveals that $19(38 \%)$ mothers from rural area initiated early weaning because of lack of support from the family members and husband's negative opinion about breast feeding ,and only 14 (28\%) mothers had lack of breast feeding advice and support from the health professionals. 75

Among urban mothers reveals that 24 (34.3\%) mothers early weaned because of husband's negative opinion about breast feeding and 20 (29\%) of mothers early weaned because of lack of breast feeding advice and support from the health care professionals. Young urban women are increasingly being separated from their own mothers and their female relations and thus have lost their traditional source of support and advice.

\section{Figure-5}

Assessment of early weaning associated with medical problems reveals that 17 (34\%) of rural mothers were early weaned because of baby was born as preterm or was admitted in NICU, 12 (24\%) mothers early weaned because of the intake of medications and history of maternal infections.

Among urban women reveals that 26 (37.1\%) mothers were having the history of maternal infections and only 21 (30\%) had regular intake of medications for illness.

\section{(Figure-6)}

Assessment of common practices among rural mothers reveals that $22(44 \%)$ mothers were having the practice of frequent weighing of child which had a negative impact on their mind,13 (26\%) mothers provided pacifiers during the first few weeks and only 11 (22\%) mothers were practiced first latch is on after more than one hour.

Among urban mothers reveals that 30 (43\%) mothers were having the practice of rooming in only in the day time, 29 (41.4\%) mothers were having the practice of frequent weighing of the child and only 26 (37.1\%) of mothers were practiced use of pacifiers during the first few week to their infants.

\section{Table - 3}

Assessment of knowledge reveals that $18(36 \%)$ of rural mothers believes that the appetite of the child will increase when the child is early weaned, $16(32 \%)$ of mothers reported that honey, water, grape water, juices and animal milk can be given to the babies in the early months and only 9 (18\%) mothers reported that breast milk is not easily digestible.

Among urban mothers knowledge reveals that 31 (44.3\%) mothers believes that if solids are taken early, baby looks healthier, 29 (41.4\%) mothers thinks that appetite increases if weaning is started early and only $15(22 \%)$ early weaned mothers perceives that breast milk is too thin in consistency

\section{Discussion}

\section{Assessment of Factors Leading To Early Weaning}

\section{Assessment the cultural practices about early weaning}

The present study result shows similar results in a cross sectional study was conducted by Dyah A Inayati and 
Veronika Scherbaumto identifies infant feeding practices among mildly wasted children on Nias Island, Indonesia. The data was collected from mothers of the children admitted to the community program .The results indicated that $6 \%$ of the mothers never breastfed and $17 \%$ discarded colostrum. Exclusive breastfeeding until 6 months of age was practiced only by $12 \%$ mothers. Seventy-four percent of the mothers offered supplementary liquids besides breast milk within the first 7 days of life, and 14\% of infants received these supplementary liquids from 7 days onwards until 6 months of age. M oreover, $79 \%$ of the infants were given complementary foods (solid, semi-solid, or soft foods) before 6 months of age. Qualitative assessments found that inappropriate infant feeding practices were strongly influenced by traditional beliefs of the mothers and paternal grandmothers in the study areas.

\section{Assessment of psychosocial influence among rural mothers}

The present study result shows similar results to a study was conducted by C M Wright, K N Parkinson and R F Drewett with the aim to examine what predicts the age of weaning and how this relates to weight gain and morbidity. Parents of 923 term infants born in a defined geographical area and recruited shortly after birth were studied. The results were the median age of first weaning solids was 3.5 months, with $21 \%$ commencing before 3 months and only $6 \%$ after 4 months of age. The strongest independent predictors of earlier age at weaning were rapid weight gain to age 6 weeks, lower socioeconomic status, and the parents' perception that their baby was hungry and feeding mode.

\section{Assessment of common barriers in continuation of breast feeding}

The present study result shows similar results in a cross sectional study was conducted by Rama Ram and M .N. Ghosh to find out the pattern of breast feeding practices in the rural mothers of Darjeeling district and influence of socio-cultural factors with special reference to occurrence of diarrhea. The sample collected from 1200 mothers attending the clinic for immunization having babies 6 weeks to 24 months. The result shows that mothers who discontinued before 6 months, $61.9 \%$ had insufficient milk and $33.1 \%$ had developed breast infections.

\section{Assessment of socio economic factors influencing early weaning}

This study results are similar to a cross sectional study was conducted by Sumera Ali, Syed Faizan Ali and Ayesha M allick Imam to identify perceptions of mothers about breastfeeding in an urban slum area of Western India. The data was collected amongst 200 mothers of children in the age group of 6 to 12 months attending the growth and development clinic in one of the urban health centers. The result shows that Prelacteal feeds were given by almost $35 \%$ of mothers. The factors of early weaning were associated with maternal education, parity and maternal occupation.

\section{Assessment of weaning associated with support from others}

This study results are similar to a study was done by Tella Adeyinka and Falaye Ajibola to examine breastfeeding behavior and practices among nursing mothers in two African countries: Nigeria and Ghana. A sample of 300 nursing mothers attending ante-natal clinic were randomly drawn from 4 hospitals, two in Nigeria and two in Ghana. The results indicate that nursing mothers do not breast-feed due to lack of social support, modeling, public enlightenment and appointment of care nursing mother.

\section{Assessment of early weaning associated with medical} problems

This study results are similar to a study conducted in Swedish countries on breast feeding. M others of 225 very preterm singleton infants were selected as samples. Seventy nine mothers breastfed till 2 months, 62 mothers till 4 months, 45 mothers till 6 months, 22 mothers till 9 months and 12 mothers' till 12 months. Prematurity, size at birth and neonatal disorders did not show an effect on breastfeeding duration. 
7. Assessment of common practices among rural mothers reveals that 22 (44\%) mothers were having the practice of frequent weighing of child which had a negative impact on their mind,13 (26\%) mothers provided pacifiers during the first few weeks and only 11 (22\%) mothers were practiced first latch is on after more than onehour.

Assessment of common practices among urban mothers reveals that $30(43 \%)$ mothers were having the practice of rooming in only in the day time, 29 (41.4\%) mothers were having the practice of frequent weighing of the child and only 26 (37.1\%) of mothers were practiced use of pacifiers during the first few week to their infants.

8. Assessment of knowledge This study results are similar to a study is conducted by R Flacking and Wallin to compare the key indicators of breast feeding and complementary feeding and their determinants in children less than 24 months of age between four South Asian countries. The result shows that exclusive breast feeding rates were $42.5 \%$ in Bangladesh and $53.1 \%$ in Nepal. In India only $46.4 \%$ mothers exclusively breast fed their children and a considerable proportion of infants less than 6 months of age had been given plain water, juices, or other non-milk liquids.

The finding in the study reveals that there are differences in factors leading the early weaning between rural and urban mother's cultural practices in early weaning, psycho social influence, common barriers in continuation of breast feeding, socio economic factors, support from others, associated with medical problems, common practices and knowledge of mothers. Hence the $\mathrm{H} 1$ is accepted that is there is a significant difference between factors leading to early weaning among mothers of infants between rural and urban area.

\section{Conclusions}

Majority of the urban 38 (76\%) and in rural 33 (47.1\%) mothers considers that weaning at 3-4 months of age is a harmless practice. Most of the rural 32(64\%) and urban $37(53 \%)$ mothers initiated early weaning because of baby will sleep throughout night without crying when fed on another feeds. Both rural 24 (48\%) and 44 (63\%) urban mothers initiated early weaning because of baby is restless and unsatisfied even after breast feeding. M ost of the rural 19(38\%) mothers initiated early weaning because of lack of support from the family members and husband's negative opinion about breast feeding whereas the urban $24(34.3 \%)$ mothers initiated early weaning because of husband's negative opinion about breast feeding. Majority of the rural $17(34 \%)$ mother's reports that they initiated the early weaning because of baby was born preterm or was admitted in NICU where as in the urban 26(37.1\%) mothers because of maternal infections.

Both rural \& urban initiated early weaning because which had a psychological influence where as in urban area they practiced rooming in only in the day time. Majority of mothers of infant from rural 24(48\%) and urban 29 (41.4\%) area initiated early weaning because of lack of maternity leave. Majority of the rural 22(44\%) mothers who have initiated the early weaning because of frequent weighing of the child whereas in urban $30(43 \%)$ early weaned because of rooming in only during day time. Majority of the rural $18(36 \%)$ mothers had the knowledge that the appetite of the child will increase when the child is early weaned whereas most of the urban 29 (41.4\%) mothers thought that if solids are given earlier baby looks healthy. There is a significant difference in the number of early weaned mothers of infant when comparing to the urban and rural areas. Hence it is concluded that the early weaning is more common in urban area than in the rural area.

\section{Nursing Implication}

Nurse educator can impart knowledge among students regarding the factors leading to early weaning among mothers of infants and nurse can also educate and council the mother and family for exclusive breast feeding to the children till 6 months age. Nurses can also arrange breast feeding supportive groups in community areas. 
The nurses can also conduct health programmes to create awareness in mothers regarding the advantages of breast feeding for both mother and child.

Research should be conducted to improve the breast feeding practices in mothers in the community as well as in the hospital.

\section{Limitations}

The study is conducted with only a small sample size thereby restricting the generalization of findings. The study samples are limited to only selected communities. The study is limited to only the factors leading to early weaning. No standardized tools were used for the study. The present study was limited to mothers who have at least one child below 1 year of age. Factors leading to early weaning was

\section{References}

1. WHO. Fifty-fourth World Health Assembly. WHA54.2. Agenda item 13.1. Infant and young child nutrition.

2. American Academy Of Pediatrics policy statement available from URL http:// www.infanet.cahs.colostate.edu

3. The under-five mortality rate: The indispensable gauge of child health available from URL http:// www.unicef.org.

4. Annual report to the people on the report September 2010 available from http://mohfw.nic.in

5. Helen C., Armstrong. The International Code of M arketing of Breast milk Substitutes available from http:// www.ilca.org

6. Breastfeeding available from http://en.wikipedia.org

7. Singh M.B, Haldiya K.R, Infant feeding and weaning practices in some semi-arid rural areas of Rajasthan.2006 available from http://www.ncbi.nlm.nih.gov.

8. Jeetender Singh,Vishakantamurthy DG."Breastfeeding practices among lactating mothers: Problems and prospects in a cross-sectional study"original article published by international journel of health and allied sciences,volume 12012.

9. Sumera Ali,Syed Faizan Ali "perception and practices of breast feeding of infants 0-6 months in urban and semi urban communities in Pakistan" available at http://lib.bioinfo.pl/pmid

10. Upul Senarath , M ichael J Dibley " Complementary feeding practices in South Asia: analyses of recent national survey data by the South Asia Infant Feeding Research Network" available at http://lib.bioinfo.pl/paper:22168515.

11. M Sowden, D Marais, R Marais "Factors influencing high socioeconomic class mothers' decision regarding formula-feeding practices in the Cape M etropole",south African journal of nutrition, available at http://www.ajol.info

12. Anurag Srivastava, Ved P Shrotriya,Payal Mishra."Infant feeding practices in the rural population of north India", journal of family and community medicine, volume 19,2012

13. Rama Ram, Ghosh M.N. "Breast Feeding Practices in the Rural Community of District Darjeeling, West Bengal" Indian journal of community medicine, available at http:// www.indmedica.com

14. Wright C M , Parkinsonand KN , Drewett R F . "Why are babies weaned early? Data from a prospective population based cohort study" original article available at dc.bmj.com/content identified only with the help of check list.

\section{Recommendations}

In the view of the findings and limitations of the present study following recommendations are offered for further research. Nurse administrators are to be motivated to prepare different teaching strategies suitable for the hospital and community regarding breast feeding.

Guidance clinics must be available for mothers and family to support for exclusive breast feeding.

A similar study can be conducted in other states to identify the factors leading to early weaning.

A similar study can be conducted using qualitative approach. 